\title{
Eleventh Annual Hydration for Health Scientific Conference: From Water Resources to Metabolic Health and Drinking Behavior
}

\author{
Evan C. Johnson ${ }^{a}$ Joan Gandy ${ }^{b}$ \\ aDivision of Kinesiology and Health, University of Wyoming, Laramie, WY, USA; breelance Dietitian, London, UK
}

The Hydration for Health (H4H) Scientific Conference moved into its second decade with a meeting held in Evian, France, on June 25th-26th, 2019. Every year since 2008 , this unique international conference has brought people together who share a common goal: to explore the relationship between hydration and health. As has become the norm, the conference was preceded by the $\mathrm{Hy}$ dration for Health Academy. Each year, the academy evolves to target the needs of the audience and this conference saw the addition of the European Association for the Study of Obesity's teaching course. The conference was split into three main sessions: Hydration and Metabolic Health, Water Resource Management, and Water and Behavior Change. The sessions were followed by an expert panel discussion that addressed the question, "How can cutting edge technology help us drink better?" The now well-established Pitch Your Science Challenge completed the program with presentations from six young hydrationists aiming to win the Young Researcher Award.

During the first decade of the $\mathrm{H} 4 \mathrm{H}$ Scientific Conference, the relationship between hydration and metabolic health generated a lot of interest [1], and this was highlighted in the first session by Dr. Tiphaine Vanhaecke's (Danone Research, Palaiseau, France) (in this issue) narrative of our current understanding regarding water intake, hormonal regulation of body water, and mechanistic management of blood glucose. The presentation began

karger@karger.com www.karger.com/anm

Karger $\stackrel{\text { ' }}{5}$

BOPEN ACCESS
(C) 2021 The Author(s)

Published by S. Karger AG, Basel

This article is licensed under the Creative Commons AttributionNonCommercial-NoDerivatives 4.0 International License (CC BYNC-ND) (http://www.karger.com/Services/OpenAccessLicense). Usage and distribution for commercial purposes as well as any distribution of modified material requires written permission. with the original presupposition that elevated arginine vasopressin (AVP) detected within individuals with type II diabetes mellitus was a compensatory result of excess water loss due to glucosuria [2]. Then on to the groundbreaking works of Enhörning and Roussel and colleagues $[3,4]$ (in this issue), that demonstrated the opposite relationship between AVP (via copeptin) and water intake with risk of diabetes and hyperglycemia, respectively. The presentation took us to the future where preclinical [5] and animal model [6] investigations have helped to further elucidate the low water intake/glucose metabolism relationship and have paved the way for ongoing clinical trials, such as that described by Dr. Olle Melander (Lund University, Lund, Sweden) later in the session. Last, we were left with unanswered questions and a road map for future investigations. Given the magnitude of glucose dysregulation on the global scale, the ease of water intake as a therapeutic, and the developing base of solid scientific evidence, this topic will be integral within Hydration for Health for years to come.

While clinicians and scientists working in the area of hydration science recognize that access to clean drinking water is essential and that water insecurity is a significant problem in many parts of the world [7], water resource management is rarely considered. As a result, the session on this topic sort to address this knowledge gap. Professor Ghislain de Marsily (University Pierre et Marie Curie, Paris, France) (in this issue) received the full attention 
from the audience by positing the question, "Will we soon run out of water?" Prof. de Marsily pragmatically broke down the numbers. If we are expected to have 11 billion people on earth by 2100 , and each person will require $1,500 \mathrm{~m}^{3} /$ year of water per year to provide food, which means $16,500 \mathrm{~km}^{3} /$ year of water will be needed! Then he walked us through how freshwater stores, the normal water cycle, and more importantly changes in our farming, and eating practices can help us meet this need. Of all the topics discussed during the conference, this clearly was the most obvious "red alert" for water researchers. However, the outlook may not be bad given that we heed the warning and pay attention to the numbers.

The two sources of water are surface water (rivers and lakes) and groundwater. Unlike surface water groundwater is normally available all year, even in arid countries, and is mainly protected from surface contamination. As a consequence, it is the main source of water for domestic needs (it is the main source of tap water), agriculture and manufacturing. Hydrogeologist Dr. Patrick Lachassagne (HydroSciences Research Institute, France) (in this issue) eloquently described the groundwater cycle, namely, the infiltration of rainwater into the soil and its slow filtration through rocks (aquifers) until it flows out at springs, into rivers, and man-made wells. Natural mineral waters, for example, Evian, are generally protected and carefully managed to ensure their purity and their unique properties that are determined by the aquifer that the water filters through. Finally, in this session, Professor Adeera Levin (University of British Columbia, Vancouver, Canada) highlighted the extensive and vital work that is being accomplished within the administration of the Global Kidney Health Atlas. This mixed methods, worldwide data collection was completed in 2017 and 2019 and aims to gather information specific to six dimensions of kidney health; health workers, financing, health policies, treatment availability, medication availability, and information systems. These studies have allowed the International Society of Nephrology to track positive trends in treatment availability between 2017 and 2019, such as the addition of four countries with capacity for peritoneal dialysis, while still being able to highlight the general paucity of registries for kidney care data within most countries. Dr. Levin finished by highlighting the important role that water availability plays in the management of kidney health and emphasized the need for continued research in this vein.

As our knowledge of the relationship between hydration and health increases, it is essential that this knowledge is used to facilitate behavior change in drinking behavior in order to improve health. With this in mind the last session of the conference, entitled Water and Behavior Change, focused on understanding behavior and attitudes to bring about behavior changes that encourage healthy drinking habits. In this supplement, Dr. Esther Papies (University of Glasgow, Glasgow, UK) discusses the psychology of desire and its implications for healthy hydration (in this issue). This article explores the psychological motivation to consume sugar sweetened beverages (SSB) by applying a grounded cognition theory of desire and motivated behavior as a way of understanding behavior and potentially changing drinking habits away from SSB towards water. SSB consumers consider drinking these sugary beverages in terms of the sensory and rewarding experiences they get from drinking them, which predicts the desire for SSBs and actual consumption. Usually, the long-term benefits of consuming healthy drinks, especially water, are emphasized. However, this theory suggests that if the emphasis is on the immediate pleasure that arises from drinking healthier drinks it may be possible to facilitate the development of healthy hydration habits. Similarly, the study by Dr. Aukje Verhoeven (Danone Research, Palaiseau, France) and colleagues (in this issue) demonstrated that pleasure and sensations were important aspects of drinking behavior in a large sample $(2,858$ participants) of Mexican adults who were identified as high sugar - low drinkers. They demonstrated that social aspects, such as sharing with family and friends and selfimage, were dominant in attitudes to life with the main reason to choose a particular drink being to get sensations that are pleasure and/or health orientated; they also identified attitude profiles including mood and pleasure. Understanding these attitudes will undoubtedly offer potential recommendations for the development of interventions aimed at promoting healthier drinking habits.

The benefits of understanding people's beliefs and attitudes can change behavior were demonstrated by Dr. Amarasiri de Silva (University of Pittsburgh, Pittsburgh, PA, USA) (in this issue). An earlier analysis of people's perception and experiences showed that people in areas of Sri Lanka where Chronic Kidney Disease of Unknown Etiology (CKDu) was endemic believed that polluted water was the leading course of $\mathrm{CKDu}$. This belief led to community agitation and activism that helped bring political attention to this issue. As a result, access to clean drinking water was improved with resulting improvements in the management of CKDu. A recent survey of people in the affected areas showed perceived benefits of safe water provisions with positive outcomes in terms of both health and disease progression in people with $\mathrm{CKDu}$. 
This year, the finalists of the Young Researcher Award presented on a diverse range of topics as shown in their abstracts published in this supplement (in this issue). The winner was Mr. Loris Juett, from the School of Sport, Department of Exercise and Health Sciences, Loughborough University, Loughborough, UK, who presented his work on the convergence of high-intensity exercise, dehydration, and the potential for acute kidney injury (AKI) (in this issue). Specifically, Mr. Juett focused on the use of novel biomarkers for evaluating AKI since the traditional marker of kidney function, serum creatinine, is confounded by the skeletal muscle breakdown inherent to high intensity physical activity. His hypothesis is that the plasma volume depletion due to exercise induced dehydration can exacerbate AKI through AVP-mediated ATP use in the kidney, as well as fructokinase creation due to hypertonicity. Although his research was laboratory and sport based its application to repeated bouts of exercise specifically associated with the CKD of an unknown origin $(\mathrm{CKDu})$ being observed in agricultural workers may be transformational as far as lessening the impact of AKI and $\mathrm{CKDu}$ worldwide. Congratulations go out to Mr. Juett and all the young researchers who provided a spark at the end of the day to get everyone excited for the coming years and the impactful research they have ahead of them.
The articles in this supplement clearly demonstrate the success of the 11th Hydration for Health conference and augur well for the current decade of conferences. We have watched as Hydration for Health has grown over the past decade from a niche grouping of presentations "about water" into a broad learning environment where the most cutting-edge hydration-related physiology, epidemiology, hydrogeology, psychology, and health policy are being shared. The snapshot provided within this special supplement is just a piece of the 11th Hydration for Health conference. Judging from these past presentations, the growth that we have observed over the past decade is bound to be doubled again in the next.

\section{Conflict of Interest Statement}

Professor Evan C. Johnson serves as a consultant to Danone Research, and received travel expenses and registration fees from Danone Research to attend the 2019 Hydration for Health Scientific Conference. He is a member of the Hydration for Health Scientific Committee since December 2020 and previously conducted human research studies that were funded by Danone Research.

Dr. Joan Gandy serves as a consultant to Danone Research. She is a member of the Hydration for Health Scientific Committee.

\section{References}

1 Perrier ET. Hydration for health: so what? ten advances in recent hydration history. Ann Nutr Metab. 2019;74(Suppl 3):4-10.

2 Zerbe RL, Vinicor F, Robertson GL. Plasma vasopressin in uncontrolled diabetes mellitus. Diabetes. 1979 May 1;28(5):503-8. Available from: http://diabetes.diabetesjournals.org/ cgi/doi/10.2337/diab.28.5.503 http://dx.doi. org/10.2337/diab.28.5.503.

3 Enhörning S, Wang TJ, Nilsson PM, Almgren $\mathrm{P}$, Hedblad B, Berglund $\mathrm{G}$, et al. Plasma co- peptin and the risk of diabetes mellitus. Circulation. 2010;121(19):2102-8.

4 Roussel R, Fezeu L, Bouby N, Balkau B, Lantieri O, Alhenc-Gelas F, et al. Low water intake and risk for new-onset hyperglycemia. Diabetes Care. 2011;34(12):2551-4.

5 Johnson EC, Bardis CN, Jansen LT, Adams JD, Kirkland TW, Kavouras SA. Reduced water intake deteriorates glucose regulation in patients with type 2 diabetes. Nutr Res. 2017 Jul;43:2532. Available from: https://linkinghub.elsevier.
com/retrieve/pii/S0271531717300489 http:// dx.doi.org/10.1016/j.nutres.2017.05.004.

6 Taveau C, Chollet C, Waeckel L, Desposito D, Bichet DG, Arthus MF, et al. Vasopressin and hydration play a major role in the development of glucose intolerance and hepatic steatosis in obese rats. Diabetologia. 2015;58(5): 1081-90.

7 Wutich A, Rosinger AY, Stoler J, Jepson W, Brewis A. Measuring human water needs. Am J Hum Biol. 2020;32(1):1-17. 